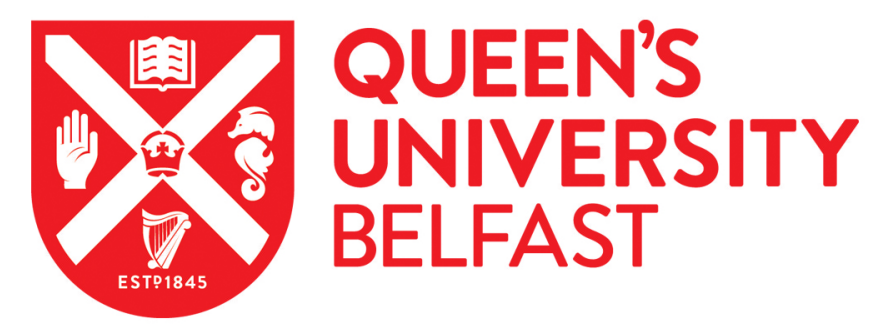

\title{
The role of the project manager in relationship management
}

Meng, X., \& Boyd, P. (2017). The role of the project manager in relationship management. International Journal of Project Management, 35(5), 717-728. https://doi.org/10.1016/j.ijproman.2017.03.001

\section{Published in:}

International Journal of Project Management

\section{Document Version:}

Peer reviewed version

\section{Queen's University Belfast - Research Portal:}

Link to publication record in Queen's University Belfast Research Portal

\section{Publisher rights}

Copyright 2017 Elsevier.

This manuscript is distributed under a Creative Commons Attribution-NonCommercial-NoDerivs License

(https://creativecommons.org/licenses/by-nc-nd/4.0/), which permits distribution and reproduction for non-commercial purposes, provided the author and source are cited.

\section{General rights}

Copyright for the publications made accessible via the Queen's University Belfast Research Portal is retained by the author(s) and / or other copyright owners and it is a condition of accessing these publications that users recognise and abide by the legal requirements associated with these rights.

Take down policy

The Research Portal is Queen's institutional repository that provides access to Queen's research output. Every effort has been made to ensure that content in the Research Portal does not infringe any person's rights, or applicable UK laws. If you discover content in the Research Portal that you believe breaches copyright or violates any law, please contact openaccess@qub.ac.uk. 


\title{
The role of the project manager in relationship management
}

\begin{abstract}
Many industry sectors are increasingly project-based. Relationship management is recognized as a focus of the next generation of project management. As a major sector, the construction industry has increasingly embraced the concept of project-based relationship management in recent years. On the other hand, project managers have grown steadily in prominence. This empirical research explores the contribution of construction project managers to relationship management through a combination of qualitative and quantitative methodologies. Relationship management in project environments can be either internal or external. This research identifies 18 roles of project managers in internal relationship management (IRM) and 18 roles in external relationship management (ERM). As a result of data analysis, they are categorized into six internal role groups and five external role groups, respectively. In addition to role identification and categorization, this research provides further evidence for the change in construction today from traditional project management that concentrates on planning and control to new project management that highlights the importance of people and working relationships.
\end{abstract}

Keywords: Relationship management; Project manager; Role; Awareness; Knowledge; Effort; Construction industry 


\section{Introduction}

Many industry sectors, such as information technology, management consulting and construction, are increasingly project-based, among which construction is probably the largest and most complex one (Sydow et al., 2004; Cheng et al., 2005; Whitley, 2006). The importance of project managers has been widely recognized in project-based industry sectors, especially in construction (Cheng et al., 2005; Turner and Müller, 2005; Papke-Shields et al., 2010). As a result, a large amount of research effort has been made to investigate project managers. Existing studies on project managers fall into five categories: (1) studies on the competency/competence of project managers, such as Crawford (2000) in general and Cheng et al. (2005) in construction; (2) studies on the selection of project managers, such as Ahsan et al. (2013) in general and Mohammadi et al. (2014) in construction; (3) studies on the leadership of project managers, such as Turner and Müller (2005) in general and Bossink (2004) in construction; (4) studies on the personality and emotional intelligence (EI) of project managers, such as Dolfi and Andrews (2007) and Zhang and Fan (2013) in construction; and (5) studies on the role of project managers, such as Ammeter and Dukerich (2002) in general and Sommerville et al. (2010) in construction. These studies as a whole contribute to an up-to-date understanding of existing knowledge of project managers as well as wider project management.

The role of project managers has been studied by a number of researchers and practitioners with different focuses. For example, Ireland (1992) examined the role of project managers in ensuring customer satisfaction. Ammeter and Dukerich (2002) addressed the role of project managers in project team building. Liebowitz and Megbolugbe (2003) looked at the role of project managers in implementing knowledge management. Blindenbach-Driessen and Ende (2006) recognized project managers as the champion of innovation management in project-based 
firms. Crawford and Nahmias (2010) emphasized the role of project managers in managing changes. Although relationship management is identified by Davis and Pharro (2003) as the next generation of project management, few studies to date have systematically investigated the role of project managers in project-based relationship management. As a result, there is a knowledge gap in this particular field. According to the Oxford English Dictionary, relationship refers to the way in which two or more people or groups feel about and behave towards each other. Bourne and Walker (2008) described project-based relationship management, simply project relationship management, as the way for a project manager and his/her team to build and maintain relationships with the right stakeholders at the right time. Similarly, Veal (2011) defined project relationship management as the active development, cultivation, and maintenance of projectassociated relationships.

In recent years, there has been increasing research evidence for relationship management in construction projects. For example, Walker and Hampson (2003) developed relationship-based procurement strategies for construction projects. Pryke and Smyth (2006) provided a relationship approach for managing complex construction projects. Davis and Walker (2009) illustrated how a construction project can be delivered through developing social relationship capital. Yeung et al. (2009) created a performance index for relationship-based construction project management. David and Love (2011) presented a structured way of relationship development to add value for construction projects. Meng (2012) demonstrated the significant effect of relationship management on project performance in construction. Jelodar et al. (2016) proposed a framework of relationship quality in construction project management. All these studies make a joint effort to describe project relationship management as a new research direction. 
Construction is generally regarded as a traditional industry sector (Miozzo and Dewick, 2004; Bennett, 2011). Traditionally, relationship management is a business issue at the corporate level and meanwhile project management focuses on planning and control, resulting in the prevalence of 'hard' management approaches in construction. Traditional approaches often lead to various problems in construction projects, such as adversarial culture and poor performance (Meng, 2012). Unlike project planning and control, relationship management highlights the importance of people in project management processes. For this reason, it is usually described as a 'soft' management approach. It can be further divided into intra-organizational relationship management and inter-organizational relationship management (Pinto et al., 2009; Pemsel and Müller, 2012). According to Mazur and Pisarski (2015), intra-organizational relationships, namely internal relationships, include the relationship between a project manager and his/her team, the relationship between different members in the project team, and the relationship between the project manager and his/her company. On the other hand, inter-organizational relationships, namely external relationships, refer to those between the project team led by its manager and external project stakeholders. Relationship-based approaches try to address traditional problems in construction projects through boosting good collaborative working within and between project organizations (Smyth, 2015).

This research attempts to bridge the gap in knowledge. It targets building construction and civil engineering projects in the United Kingdom (UK). It pays particular attention to relationship management in project environments. It aims to explore how construction project managers perform in relationship management internally and externally. The objectives of this research include (1) investigating the awareness and knowledge of project managers about relationship management; (2) measuring the extent of project managers' effort for relationship 
management; (3) analyzing the impact of IRM and ERM on project performance in terms of time, cost, quality and client satisfaction; and (4) identifying the role of project managers in IRM and ERM. This research mirrors the shift in construction from planning and control-based project management in hard to relationship-oriented project management in soft, which implies that the construction industry is replacing traditional management philosophies with new management paradigms. It provides researchers and practitioners with deeper insights gained from construction practice today. Although it is based on construction projects, its findings may also be useful for project management in other industry sectors.

\section{Literature review}

The literature review categorizes existing studies on project managers in terms of their competency/competence, selection, leadership, personality, and role. Among the studies on project managers, competency/competence has attracted the most research attention. For example, Crawford (2000) in general created a profile of competent project managers. Clarke (2010) in general grouped 24 competence elements selected from the Project Manager Competency Development Framework of the Project Management Institute into four competence measures: communication, teamwork, attentiveness, and conflict management. Bredillet et al. (2015) in general provided definition and assessment approaches to look at "what is a competent project manager?" from the Aristotelian perspective, and believed that the project manager should be 'wise' and act 'rightly' or do 'good' action in order to become competent. On the other hand, Cheng et al. (2005) in construction presented a competency-based model for the performance of project managers to answer "what makes a good project manager?" in the UK, in which twelve competencies are achievement orientation, initiative, information seeking, focus on client's needs, impact and influence, directiveness, teamwork and cooperation, team leadership, 
analytical thinking, conceptual thinking, self-control, and flexibility. Ahadzie et al. (2008) in construction developed competence-based measures for the performance of construction project managers in developing countries, encompassing four task competencies (cognitive ability, job knowledge, task proficiency, and experience) and two contextual competencies (job dedication, and interpersonal facilitation).

Selecting the right project manager is a challenge for any project-based organization (Ahsan et al., 2013). A competency/competence development framework can be used to evaluate past performance and predict future performance of project managers. For example, Hadad et al. (2013) in general and Zavadskas et al. (2008) in construction took competency/competence and performance into consideration when selecting project managers. They believed that project manager selection should be based on competency/competence assessment and performance evaluation. As a general study, Ahsan et al. (2013) identified communication, technical skills, stakeholder management, cost management, time management, education background, planning, leadership, team building, and professional certification as the top ten criteria for project manager selection. According to Mohammadi et al. (2014) in construction, decision making for project manager selection always involves complexity and uncertainty. For this reason, establishing appropriate and systematic criteria is crucial for successful project manager selection, which must reflect the project client's needs and expectations.

Following competency/competence development and project manager selection, leadership has become another hot research topic about project managers. Many studies, such as Crawford (2000) in general and Cheng et al. (2005) in construction, have recognized project team leadership as an important component of project managers' competency/competence. According to Turner and Müller (2005) in general, there are different styles of project team leadership. 
Rowlinson et al. (1993) and Bossink (2004) investigated different leadership styles in construction projects. Yang et al. (2011) in general and Odusami et al. (2003) in construction established a linkage between project team leadership and project success. Müller and Turner (2007) and Malach-Pines et al. (2009) in general and Ogunlana et al. (2002) and Udhayakumar and Karthikeyan (2014) in construction highlighted the fit of leadership styles to project types and project teams. The use of appropriate leadership is commonly understood by these studies as a strategic approach to develop competitive advantages for project management.

The literature review shows various research interests in the personality and EI of project managers. According to Dolfi and Andrews (2007), rather than pessimistic, it is important for project managers to be optimistic because the optimism of project managers helps them to overcome difficulties in working environments no matter whether it is innate or learned. Compared to introverted project managers, Bevilacqua et al. (2014) believed that extroverted project managers are more likely to improve project performance and achieve project success. The personality traits of project managers affect their leadership qualities (Burke and Barron, 2007). On the other hand, the EI and personality of project managers impact on their competency/competence (Davis, 2011). Among construction studies on the personality of project managers, Haynes and Love (2004) proposed that project managers with different personality traits may differ in terms of psychological adjustment to working stress. Wang et al. (2016) concluded that project managers with different personality traits may perceive risks and deal with risks in different ways. Zhang and Fan (2013) suggested that the EI and personality of project managers have a significant effect on team communication, conflict management and team leadership. 
As mentioned above, some general studies have identified the role of project managers in customer satisfaction, team building, knowledge management, innovation management, and change management. More importantly, Sommerville et al. (2010) thought that construction project managers have a collection of roles to play, such as decision maker, safety coordinator, organizer, team worker, motivator, planner, process controller, inspector, diplomat, quality coordinator, communication facilitator and implementer, and what role a construction project manager will actually play depends on personal maturity and project nature. In spite of that, the role of project managers in relationship management has been little studied in a systematic and specific way. The signal of project managers' role can only be observed from the studies on some particular topics about project relationship management.

Trust and teamwork are two of such research topics. Munns (1995) in general and Wong et al. (2000) in construction highlighted the importance of project managers developing intraorganizational trust to team performance and project success. Anantatmula (2010) in general and Fong and Lung (2007) in construction suggested that project managers make effort for interorganizational trust, based on which it becomes possible for project partners to work collaboratively with each other. According to Wong et al. (2000) on intra-organizational trust and Meng (2015) on inter-organizational trust as two construction studies, trust is generally acknowledged as a fundamental element of working relationships. On the other hand, Anantatmula (2010) in general believed that project managers should pay attention to both intraorganizational and inter-organizational teamwork. In terms of intra-organizational teamwork, it is consistent with Ammeter and Dukerich (2002) in general. It also supports Fong and Lung (2007) in construction in terms of inter-organizational teamwork. Similar to Anantatmula (2010) in general, Chen and Partington (2004) in construction perceived that both intra-organizational 
and inter-organizational teamwork rely on collaborative culture as the focus of close working relationships and project managers' conception of relationships.

Relationship performance and relationship quality are two others of such research topics. Yeung et al. (2009) divided the relationship performance index into relationship-oriented objective measures and relationship-oriented subjective measures. Relationship-oriented objective measures consisted of the occurrence and magnitude of claim, dispute and litigation and the introduction of facilitated workshop, whereas relationship-oriented subjective measures included trust and respect, effective communications, harmonious working arrangement, longterm business, top management commitment, employee's attitude, and reduction of paperwork. Project managers can use the index to measure, monitor and improve the performance of relationship management in construction projects. On the other hand, Jelodar et al. (2016) identified teamwork, commitment and trust as the three attributes of relationship quality when developing the relationship quality framework, all of which cannot be achieved without the help of project managers.

\section{Research methods}

This research started with a comprehensive review of relevant literature in both general and construction. The literature review provided an up-to-date understanding of existing knowledge about project managers. It also helped the authors of this paper to identify the need for an empirical investigation in this research. There were two main sources for identifying the role of project managers in relationship management: one was the review of relevant literature and the other was the interviews with a group of industrial experts. Relevant literature here includes the literature on the overall role of project managers, such as Sommerville et al. (2010), and the literature on some particular research topics about project relationship management, e.g. (1) 
Munns (1995) and Anantatmula (2010) in general and Wong et al. (2000) and Meng (2015) in construction for intra-organizational and/or inter-organizational trust; (2) Ammeter and Dukerich (2002) and Anantatmula (2010) in general and Chen and Partington (2004) and Fong and Lung (2007) in construction for intra-organizational and/or inter-organizational teamwork; and (3) Yeung et al. (2009) that provided relationship-oriented performance measures and Jelodar et al. (2016) that identified relationship quality attributes in construction projects. On the other hand, some useful information about project relationship management within existing studies on project managers' competency/competence, leadership and personality, such as Crawford (2000) and Clarke (2010) in general and Cheng et al. (2005) and Ahadzie et al. (2008) in construction for competency/competence development, Müller and Turner (2007) in general and Udhayakumar and Karthikeyan (2014) in construction for leadership styles and qualities, and Dolfi and Andrews (2007) in general and Zhang and Fan (2013) in construction for personality and EI, contributes to the identification of their roles in relationship management.

On the other hand, the interviews with industrial experts who were knowledgeable and experienced in project relationship management confirmed the role of project managers identified from the literature review. In-depth information about project relationship management was also collected from the interviews in qualitative. The semi-structured approach was adopted for the interviews. Each interview lasted approximately one hour. The industrial experts were interviewed face to face or through telephone. Based on the literature review and expert interviews, 18 roles in IRM and 18 roles in ERM were identified and confirmed for construction project managers. The roles in IRM are balanced with the roles in ERM.

A questionnaire survey was used to gather quantitative date about project managers in the context of relationship management. In this research, the questionnaire survey was the main 
instrument for data collection. It was project-specific, which means that each questionnaire response represented a building construction or civil engineering project recently completed in the UK. The questionnaire is divided into six sections. Section 1 refers to a respondent's position and experience in project management as well as project type (newly built project or repair/refurbishment project). Section 2 focuses on the respondent's awareness and knowledge of relationship management. Section 3 measures the extent to which the respondent as a project manager made effort for overall relationship management, IRM and ERM. In Section 4, the impact of IRM and ERM on project performance is rated in terms of time, cost, quality, and client satisfaction. Section 5 is designed to identify the role of the respondent as a project manager in IRM and ERM. Section 6 allows the respondent to provide any additional comments on project relationship management.

In this research, the questionnaire was pre-tested through a pilot study for its applicability. Comments and suggestions provided by a group of researchers and practitioners contributed to its modification and finalization. Subsequent to the pilot study, the finalized questionnaire was sent to approximately 200 building construction, civil engineering and project management firms with different sizes selected across the UK. E-mail was used to collect questionnaire responses because it would be quicker and cheaper than postal service and meanwhile easier to get access to potential respondents. The positions of potential respondents in the 200 firms were related to project relationship management. A respondent was asked to complete the questionnaire based on a building construction or civil engineering project he/she had experienced recently. An introduction was provided at the beginning of the questionnaire so that every respondent could have a good understanding of the survey purpose. In order to increase the response rate, the introduction encouraged any respondent to return more than one response if he/she had useful 
experience in more than one recent project or to forward the questionnaire to other colleagues if they were in better positions to answer it.

\section{Analysis of quantitative data}

The questionnaire survey resulted in the collection of 73 responses with the response rate of 36.5\%. Among the 73 respondents, $61(83.6 \%)$ were construction project managers. In addition to the vast majority of project managers as survey respondents, $12(16.4 \%)$ responses in the survey came from senior managers in building construction, civil engineering and project management firms, who had recent experience in relationship management as project managers or project directors. The 73 responses consisted of $48(65.8 \%)$ newly built projects and 25 (34.2\%) repair/refurbishment projects. As a result, the sample provided surveyed projects by different types and with different sizes.

\subsection{Awareness and knowledge of relationship management}

In the questionnaire, Section 2 is used to rate a respondent's awareness and knowledge of project relationship management at five different levels: low $(=1)$; low-to-medium $(=2)$; medium $(=3)$; medium-to-high $(=4)$; and high $(=5)$. For the awareness of relationship management, 11 $(15.1 \%)$ respondents rated their awareness at the medium level; $35(47.9 \%)$ respondents rated their awareness at the medium-to-high level; and 27 (37.0\%) respondents rated their awareness at the high level. No responses to the awareness of relationship management are found at the low level or at the low-to-medium level. For the knowledge of relationship management, on the other hand, $6(8.2 \%)$ respondents rated their knowledge at the low-to-medium level; $30(41.1 \%)$ respondents rated their knowledge at the medium level; 26 (35.6\%) respondents rated their knowledge at the medium-to-high level; and $11(15.1 \%)$ respondents rated their knowledge at the 
high level. There is no statistical evidence for the knowledge of relationship management at the low level. The finding suggests that the majority of project managers today realize the importance of relationship management and meanwhile they have at least basic knowledge of relationship management. The mean value of awareness is 4.2192 , whereas that of knowledge is 3.5753. By comparison, the average knowledge of relationship management falls behind the average awareness of relationship management. Obviously, it is relatively easier for project managers to enhance their awareness. In order for them to deal with relationship issues, more effort is needed to develop their knowledge and skills.

The analysis of questionnaire responses shows that 15 (20.5\%) respondents had 1-5 years of experience as a project manager (Group 1); 49 (67.1\%) respondents had 6-15 years of experience as a project manager (Group 2); and $9(12.3 \%)$ respondents had more than 15 years of experience as a project manager (Group 3). The mean values of the awareness of relationship management are: 4.2000 for Group 1; 4.2041 for Group 2; and 4.3333 for Group 3. On the other hand, 3.4000 for Group 1, 3.6122 for Group 2 and 3.6667 for Group 3 are the mean values of the knowledge of relationship management, respectively. One-way analysis of variance (ANOVA) is used to test the differences in mean values among the three groups, whose results are $F=0.136$ and Sig. $=0.873$ for the awareness of relationship management, and $F=0.412$ and Sig. $=0.664$ for the knowledge of relationship management. Although there are no significant differences among the three groups, it is possible to observe a general trend: the longer a person works as a project manager the higher level of awareness and knowledge he/she has. Compared to the difference between Groups 1 and 2, the awareness of relationship management witnesses a bigger difference between Groups 2 and 3. In contrast, there is a bigger difference in the knowledge of relationship management between Groups 1 and 2 than the difference between Groups 2 and 3 . 


\subsection{Effort for relationship management}

In Section 3 of the questionnaire, how much overall effort a respondent made in his/her selected project for relationship management is first rated at five different levels: $1-20 \%(=1)$; $21-40 \%(=2) ; 41-60 \%(=3) ; 61-80 \%(=4)$; and $81-100 \%(=5)$. The analysis of questionnaire responses shows that $10(13.7 \%)$ respondents dedicated $21-40 \%$ of their effort; $20(27.4 \%)$ respondents dedicated $41-60 \%$ of their effort; 38 (52.1\%) respondents dedicated $61-80 \%$ of their effort; and $4(5.5 \%)$ respondents dedicated $81-100 \%$ of their effort for overall relationship management. On the other hand, $1-20 \%$ of effort was answered by only one (1.4\%) respondent. The finding provides clear evidence that relationship management is the first and foremost what project managers usually do in today's construction practice. In other words, the importance of relationship management to project success is highlighted today much more strongly than ever before in construction.

The second question in Section 3 of the questionnaire measures the respondent's effort for IRM and ERM in his/her selected project. As a result, it is possible to compare the dedication to IRM and that to ERM. $26(35.6 \%)$ respondents made more effort for IRM, whereas 46 (63.0\%) respondents made nearly equal effort for IRM and ERM. More effort for ERM was answered by only one (1.4\%) respondent. IRM refers to managing the relationship between a project manager and his/her team, the relationship between team members under his/her leadership, and the relationship with his/her company. On the other hand, managing the relationships between the project manager's team and other project stakeholders, such as client and suppliers, is the focus of ERM. It is found that most of time project managers today pay equal attention to IRM and ERM and sometimes they pay more attention to IRM. Although it is rare to see more attention to ERM, ERM is an indispensable part of relationship management. This is because every 
respondent made more or less effort for ERM and meanwhile the effort made by almost all the respondents for ERM accounts for at least $20 \%$ of the total effort.

\subsection{Impact of relationship management on project performance}

In Section 4 of the questionnaire, the impact of IRM and ERM on project performance in terms of time, cost, quality and client satisfaction is assessed in a surveyed project according to a five-point Likert scale, ranging from very low $(\mathrm{VL}=1)$, through low $(\mathrm{L}=2)$, neutral $(\mathrm{N}=3)$ and high $(\mathrm{H}=4)$, to very high $(\mathrm{VH}=5)$. The respondents' perception is quite positive because there are no responses of $\mathrm{VL}$ and $\mathrm{L}$ to both the impact of IRM and the impact of ERM on project performance in terms of time, cost, quality and client satisfaction. In addition to no responses of $\mathrm{VL}$ and $\mathrm{L}$, there are even no responses of $\mathrm{N}$ to the impact of ERM on client satisfaction. The finding demonstrates that relationship management should be a decisive consideration if project performance is to be improved. It deserves a tremendous effort internally and externally because of its high level of contribution to the improvement of project performance in four key areas. Without effective relationship management, there will be little or no hope for project performance improvement.

The mean values of impact assessment are shown in Table 1. Based on means comparison, the ranking of mean values is also presented in Table 1. Obviously, relationship management does not have equal importance to project performance in four key areas. Instead, the impact on cost performance is the top one in the internal relationship group, whereas the impact on client satisfaction is the top one in the external relationship group. If a comparison is made among time, cost and quality performance, it is found that relationship management has the greatest impact on cost performance, which is followed by time performance. On the other hand, the impact of relationship management on quality performance is smallest. This trend is the same for both IRM 
and ERM. Another interesting finding is that the impact of relationship management on client satisfaction ranks last in the internal relationship group, whereas it ranks first in the external relationship group. The greatest impact of ERM on client satisfaction provides a remarkable contrast with the smallest impact of IRM on client satisfaction.

Table 1

Impact of relationship management on project performance.

In the performance areas of time, cost and quality, the mean values of IRM's impact are all greater than those of ERM's impact. For example, the mean value of IRM's impact on time performance is 4.2603, whereas that of ERM's impact on time performance is 4.0137. Clearly, IRM contributes more than ERM to project performance in terms of time, cost and quality. If performance in these three areas is to be improved, IRM should have a higher priority. To a certain extent, the finding explains why sometimes project managers invest more effort for IRM and meanwhile it is rare to see more effort for ERM. Unlike the impact on time, cost and quality performance, ERM has a greater impact on client satisfaction compared to IRM. For this reason, project managers should place more emphasis on ERM if client satisfaction is to be improved in construction project management practice.

A comparison is further made for the impact of IRM and ERM on project performance in terms of time, cost, quality and client satisfaction between newly built projects and repair/refurbishment projects (see Table 1). It is clearly found that the mean values of IRM and ERM's impact on project performance in newly built projects are all greater than those in 
repair/refurbishment projects. Compared to a repair/refurbishment project, a newly built project is generally larger and more complex, in which a larger number of project parties are involved and meanwhile various working relationships comprise a more complex social network system. For large and complex projects, relationship management may play a more important role in project success. That is to say, the larger and more complex a construction project is, the more emphasis people may have to place on relationship management.

Based on independent sample t-test, significant differences between the two types of projects, or the two groups, can be found more frequently for ERM than for IRM. This means that, compared to IRM, the relative importance of ERM to project performance increases more dramatically when projects become larger and more complex. Instead of IRM's impact on time and cost performance, significant difference can only be found for IRM's impact on quality performance between the two groups. On the other hand, the difference between the two groups for ERM's impact on quality performance is more significant than those for ERM's impact on time and cost performance. The findings illustrate that, compared to time and cost performance, quality performance attracts attention from relationship management more quickly when projects become larger and more complex although on the whole relationship management for quality performance is not as important as that for time and cost performance.

\subsection{Roles of project managers in IRM and ERM}

Section 5 of the questionnaire provides a list of 18 roles of project managers in IRM and 18 roles of project managers in ERM. The role of a respondent as a construction project manager in IRM and ERM is rated according to a five-point Likert scale: strongly disagree $(\mathrm{SD}=1)$; disagree $(\mathrm{D}=2)$; neutral $(\mathrm{N}=3)$; agree $(\mathrm{A}=4)$; and strongly agree $(\mathrm{SA}=5)$. The comparison of mean values shows the top five roles of project managers in IRM as follows: 
- Creating good communication channels with team members (Mean=4.7945);

- Developing trust between project manager and team members (Mean=4.7945);

- Encouraging open and effective communication between team members (Mean=4.7534);

- Fostering trust between different team members (Mean=4.6712); and

- Listening carefully and responding actively to team members (Mean=4.6712).

On the other hand, the top five roles of project managers in ERM are listed below through means comparison:

- Developing trust between own team and other project parties (Mean=4.7808);

- Facilitating open and effective communication between own team and other project parties $($ Mean=4.7397);

- Developing long-term business relationship with client (Mean=4.6849);

- Establishing a good dialogue with local social communities (Mean=4.6164); and

- Developing long-term business relationships with suppliers (Mean=4.5753).

Factor analysis is a statistical method to interpret the meaningful relationship among many correlated variables through aggregating them into a few underlying components. It is used in this research for dimension reduction. As a result of factor analysis, 18 variables that describe a project manager's roles in IRM are grouped into six components namely: (1) intra-organizational communication and trust; (2) team cohesion and motivation; (3) conflict resolution and equal treatment; (4) empowerment and team morale; (5) senior management support; and (6) learning and innovation (see Table 2). The adequacy of Kaiser-Meyer-Olkin (KMO) test is 0.766 , and the significance of Bartlett's test is 0.000. Obviously, each of the six components reflects a key aspect in which project managers contribute to IRM. 
Table 2

Rotated component matrix for internal roles of a project manager.

On the other hand, factor analysis results in the classification of 18 variables that describe a project manager's roles in ERM into five components, including (1) inter-organizational communication, trust and long-term business with client and suppliers; (2) collaborative working between project parties; (3) mutual understanding and objectives; (4) working with other project stakeholders; and (5) compliance with contracts and regulations (see Table 3). The adequacy of KMO test is 0.701 , and the significance of Bartlett's test is 0.000 . Similar to each of the six components for IRM, each of the five components here can be used to describe a key aspect in which project managers contribute to ERM.

Table 3

Rotated component matrix for external roles of a project manager.

Reliability analysis (Cronbach Alpha) is a measure of internal consistency and unidimensionality to see how closely related a set of items are as a group. In this research, it is used for the variables that are grouped into each internal or external component. For the role of project managers in IRM, Cronbach Alpha is 0.843 for Component 1 (very good), 0.766 for Component 2 (good), 0.759 for Component 3 (good), 0.631 for Component 4 (moderate), and 0.799 for Component 5 (good). Since there is only one variable in Component 6 , it is not necessary to make reliability analysis. On the other hand, reliability analysis of project 
managers' role in ERM results in Cronbach Alpha of 0.831 for Component 1 (very good), 0.729 for Component 2 (good), 0.639 for Component 3 (moderate), 0.920 for Component 4 (excellent), and 0.660 for Component 5 (moderate). Obviously, each component grouped by factor analysis is reliable in terms of internal consistency and unidimensionality.

The results of factor analysis confirm that both IRM and ERM require communication and trust. Construction project managers have to pay the greatest attention to both intraorganizational and inter-organizational communication and trust because they provide a prerequisite for project team building and supply chain collaboration. Although a project is temporary, inter-organizational communication and trust present a starting point of developing long-term business relationships between project parties. The finding explains why the first component for project managers' contribution to ERM covers both inter-organizational communication and trust and long-term business opportunities. From the internal perspective, the second important component is team cohesion and motivation. On the other hand, collaborative working between project parties is the second important component from the external perspective. For both internal team cohesion and external collaborative working, construction project managers always have important roles to play. For internal team cohesion, project managers should integrate individual interests towards overall project objectives, clearly define roles and responsibilities for each team member, motivate the whole team for high-performance working, etc. For external collaborative working, on the other hand, project managers should encourage clear definition of roles and responsibilities, joint effort, joint decision-making between project parties, etc.

Conflict resolution and equal treatment form the third component for internal relationships, whereas problem solving with a similar meaning to conflict resolution is involved in the second 
component for external relationships, which means that effective problem solving is a part of collaborative working between project parties. On the other hand, mutual understanding and objectives characterize the third component for external relationships. In order for project parties to work collaboratively together, they have to establish mutual objectives based on a good understanding of each other's concerns and expectations. As the leader of a construction team, a project manager has many important things to do for mutual understanding and objectives. For example, benefit and risk sharing makes it more possible for project parties to establish and achieve mutual objectives because it is the core principle of collaborative working. Unlike "Listening carefully and responding actively to team members" classified into the component "Intra-organization communication and trust" for IRM, "Listening carefully and actively responding to concerns raised by other project parties" is classified into the component "Mutual understanding and objectives" for ERM. Listening carefully and actively responding is a communication skill. If a project manager listens carefully and responds actively to other project parties, it becomes easier to create harmonious environments. As a result, project parties are more likely to obtain mutual understanding and achieve mutual objectives.

Empowerment and team morale, senior management support, and learning and innovation are the last three aspects in which a project manager contributes to IRM. Senior management support is a separate component in which two roles of a project manager refer to the relationship between the project manager and his/her company. This is different from some other roles of a project manager in IRM, such as "Fostering trust between different team members" and "Developing trust between project manager and team members" that are grouped into the same component but represent the relationship between the project manager and his/her team and the relationship between different team members, respectively. The finding illustrates that the relationship with 
the company is relatively independent when looking at internal relationships and meanwhile senior management support cannot be underestimated in terms of its importance to project success. On the other hand, working with other project stakeholders and compliance with contracts and regulations are the last two aspects in which a project manager contributes to ERM. Although client and suppliers are supply chain partners that attract the most attention from a project manager, it is not possible for the project manager to overlook or ignore the relationship with other project stakeholders, such as trade unions, public media, local communities, and government bodies.

\section{Analysis of qualitative data}

This research adopts a combination of a questionnaire survey in quantitative and expert interviews in qualitative. Prior to the questionnaire survey, a group of industrial experts were interviewed. Similar to the questionnaire respondents, the interviewees in this research held such management positions as project manager, senior manager or key member in a project team. All of them had more than five years of work experience in the construction industry. As mentioned above, the interviewees confirmed the role of project managers in IRM and ERM identified from the literature review. They also provided clear evidence for project relationship management in construction practice. A consensus between the interviewees and the questionnaire respondents is that project managers in construction are paying growing attention to both IRM and ERM. The interviewees believed that, rather than staying on the slogan, many project managers today are active to practice relationship management consciously. The analysis of questionnaire responses suggests a greater impact of relationship management on project performance in newly built projects than in repair/refurbishment projects. Likewise, the interviewees pointed out that, 
compared to small and simple projects, relationship management is more important in large and complex projects where it deserves more effort.

A questionnaire survey is limited to standard questions and answers. In contrast, an interview is good at gathering in-depth information. The interviewees in this research provided some deeper insights into relationship management in construction projects as well as project managers for relationship management. For example, the effort for relationship management not only relates to project managers' awareness and knowledge in relationship management but also depends on previous experience in cooperation between project parties or between project team members. More effort needs to be made for relationship management if project parties or project team members have no previous experience in cooperation because they have to get familiar with each other from the very beginning. For this reason, working together happily and effectively before should be very useful for project parties or project team members to develop good relationships between teams or within teams in new environments.

Generally, the questions involved in a questionnaire have to remain constant, assuming that there is no change for the background as time goes. For relationship management, it may lead to misunderstanding. According to the interviewees in this research, relationship management in construction projects is usually a dynamic process. This means that working relationships may change from time to time. When project parties or project team members get on well during a project, the project manager does not need to make much effort for ERM or IRM. However, project managers meet challenges when encountering problems, conflicts and disputes. In order for good relationships to keep going, it is crucial to resolve problems, conflicts and disputes as quickly as possible and at the lowest possible level. If satisfactory solutions cannot be found for 
problems, conflicts and disputes, it is not uncommon for good relationships to be broken. Once good relationships become absent, huge effort is required to restore them.

\section{Discussion}

Relationship management is considered by Davis and Pharro (2003) as the next generation of project management. In this sense, project managers are increasingly looking like relationship managers. This is mainly because a project and a project manager cannot succeed without the help of senior management, project team, and external stakeholders (Godbold, 2003). The literature review in this research reveals that three relevant theories have emerged over the past two decades: project marketing, relational contracting, and stakeholder management. According to Cova and Salle (2005), project marketing emphasizes the transaction and brings a wider perspective to project management with the focus of developing and maintaining relationships. Yeung et al. (2012) viewed relational contracting as cooperative relationships between project parties based on the recognition of mutual benefits and win-win scenarios. Mazur and Pisarski (2015) believed that the management of internal and external stakeholders is the responsibility of project managers. Obviously, all these three theories point to working relationships. For this reason, relationship management has become a center of modern theories of project management. This research resonates with earlier studies on relationship management in project environments. On the other hand, it goes one step further than earlier studies.

This research looks at relationship management mainly from the perspective of project managers. Actually, earlier studies have started to pay attention to the role of project managers in relationship management. For example, Walker (2013) in general suggested that project managers must lead or influence others and ensure that relationship effort is sustained. In construction, Sommerville et al. (2010) identified a collection of roles for project managers, 
some of which have relevance to relationship management. However, earlier studies either are not specific to project managers' role in relationship management or do not provide empirical evidence to support their arguments. This research is probably the first attempt to empirically investigate the role of project managers in relationship management in a specific way. Based on the analysis of qualitative and quantitative data, it provides a useful framework to guide project managers for effective relationship management. It also enriches the previous literature that encourages the use of relationship-based approaches in project environments.

Among existing studies, some of them focus on internal relationships, whereas others target at external relationships. For example, Peterson (2007) in general and Doloi (2007) in construction identified the key factors that motivate project team members for teamwork and collective action from the intra-organizational perspective. On the other hand, Mohr and Spekman (1994) in general and Walker and Loosemore (2003) in construction considered joint problem solving as an effective way of encouraging collaborative working between project parities from the interorganizational perspective. Few studies have interest in both internal and external relationships. Unlike most of the existing studies, this research covers both IRM and ERM when studying the role of project managers. The coverage reflects the fact that both internal and external relationships are important for project success. Although it is found in this research that IRM has a greater impact on project performance in terms of time, cost and quality whereas ERM has a greater impact on client satisfaction, it is not appropriate for project managers to ignore or underestimate either of them.

According to many studies on project management, such as Kuster et al. (2015) in general and Walker (2015) in construction, project management requires systems thinking. Planning and control describes the hard side of project management. On the other hand, relationship 
management characterizes the soft side of project management. For relationship management as a social network system in project management, it can be divided into two parts: IRM and ERM. IRM consists of six components, whereas ERM includes five components. Each component represents an aspect of working relationships, or an element in the relationship management system. Different parts and elements in the relationship management system are not isolated. Instead, they influence each other and interact with each other. Systems theory tell us that it is only possible to achieve the overall success when all parts and elements in the system work together very well. For this reason, project managers should take different parts and elements into consideration when making decisions for relationship management.

\section{Conclusions}

Increasing emphasis on project-based relationship management is a trend in the construction industry today. This empirical research provides convincing evidence for the significant contribution of project managers to relationship management in project environments. This can be seen from the high levels of their effort for relationship management and the important roles they play in relationship management. As a result of factor analysis, 18 roles for internal relationships are categorized into six components, whereas 18 roles for external relationships are categorized into five components. Intra-organizational communication and trust rank first among the six components for internal relationships. Similarly, inter-organizational communication and trust as well as long-term business rank first among the five components for external relationships. Undoubtedly, good communication and mutual trust lay an essential foundation for both internal and external relationship development. In addition to intra-organization communication and trust, other relationship components for internal roles of project managers include team cohesion and motivation, conflict resolution and equal treatment, empowerment 
and team morale, seeking senior management support, and learning and innovation. For external roles of project managers, collaborative working between project parties, mutual understanding and objectives, working with other project stakeholders, and compliance with contracts and regulations are the relationship components other than inter-organizational communication and trust as well as long-term business.

Project manager have to pay attention to both IRM and ERM. They have also to pay attention to different aspects of relationship management represented by different relationship components. In other words, they have to be versatile in respect to project-based relationship management. This research reveals that the effort of project managers for IRM is rarely less than their effort for ERM. This is mainly because IRM has a greater impact on project performance in terms of time, cost and quality than ERM and meanwhile time, cost and quality are three major objectives of managing construction projects. Unlike time, cost and quality performance, client satisfaction is more influenced by ERM instead of IRM. The more importance of ERM to client satisfaction shows that ERM deserves the effort of project managers because client satisfaction is as important as the successful accomplishment of time, cost and quality objectives. The effort of project managers for IRM contributes to project team building and development. On the other hand, their effort for ERM contributes to supply chain collaboration and external stakeholder engagement. Better internal and external environments create more opportunities to improve project performance and achieve project success. This explains why both IRM and ERM are increasingly highlighted in construction projects.

This research contributes to the body of knowledge because it presents empirical evidence for why relationship management is important for project success and how project managers can effectively manage internal and external relationships. Based on existing studies, it provides 
researchers and practitioners with further confidence in project-based relationship management as a new direction. In spite of that, it has several limitations. Although the empirical investigation is successful, the number of questionnaire responses and interviews is still not large enough. Focus on construction projects may be another limitation of this research. More thorough data collection is recommended for future research. According to the interviewees in this research, relationship management varies from project to project. Each project is characterized by its own way of relationship management. For this reason, it is possible to adopt case study methodology in future research and conduct within and cross case analysis. Recommendation may also include the comparison of project-based relationship management between construction and other industry sectors to better understand its principles and paradigms.

\section{References}

Ahadzie, D.K., Proverbs, D.G., Olomolaiye, P., 2008. Towards developing competency-based measures for construction project managers: should contextual behaviors be distinguished from task behaviors? International Journal of Project Management, 26(6), 631-645.

Ahsan, K., Ho, M., Khan, S., 2013. Recruiting project managers: a comparative analysis of competencies and recruitment signals from job advertisements. Project Management Journal, 44(5), 36-54.

Ammeter, A.P., Dukerich, J.M., 2002. Leadership, team building, and team member characteristics in high performance project teams. Engineering Management Journal, 14(4), 3-10.

Anantatmula, V.S., 2010. Project manager leadership role in improving project performance. Engineering Management Journal, 22(1), 13-22.

Bennett, J., 2011. Construction the Third Way: Managing Cooperation and Competition in Construction. Routledge, Oxon. 
Bevilacqua, M., Ciarapica, F.F., Germani, M., Mazzuto, G., Paciarotti, C., 2014. Relation of project managers' personality and project performance: an approach based on value stream mapping. Journal of Industrial Engineering and Management, 7(4), 857-890.

Blindenbach-Driessen, F., Ende, J.V.D., 2006. Innovation in project-based firms: the context dependency of success factors. Research Policy, 35(4), 545-561.

Bossink, B.A.G., 2004. Effectiveness of innovation leadership styles: a manager's influence on ecological innovation in construction projects. Construction Innovation, 4(4), 211-228.

Bourne, L., Walker, D.H.T., 2008. Project relationship management and the Stakeholder Circle. International Journal of Managing Projects in Business, 1(1), 125-130.

Bredillet, C., Tywoniak, S., Dwivedula, R., 2015. What is a good project manager? An Aristotelian perspective. International Journal of Project Management, 33(2), 254-266.

Burke, R., Barron, S., 2007. Project Management Leadership: Building Creative Teams. Burke Publishing, London.

Chen, P., Partington, D., 2004. An interpretive comparison of Chinese and Western conceptions of relationships in construction project management work. International Journal of Project Management, 22(5), 397-406.

Cheng, M., Dainty, A.R.J., Moore, D.R., 2005. What makes a good project manager? Human Resource Management Journal, 15(1), 25-37.

Clarke, N., 2010. Emotional intelligence and its relationship to transformational leadership and key project manager competences. Project Management Journal, 41(2), 5-20.

Crawford, L., 2000. Profiling the competent project manager. Proceedings of PMI Research Conference, 21-24 June, 2000, Paris, France, pp. 3-15.

Crawford, L., Nahmias, A.H., 2010. Competencies for managing changes. International Journal of Project Management, 28(4), 405-412.

Cova, B., Salle, R., 2005. Six key points to merge project marketing into project management. International Journal of Project Management, 23(5), 354-359. 
Davis, P.R., Walker, D.H.T., 2009. Building capability in construction projects: a relationship-based approach. Engineering, Construction and Architectural Management, 16(5), 475-489.

Davis, P., Love, P., 2011. Alliance contracting: adding value through relationship development. Engineering, Construction and Architectural Management, 18(5), 444-461.

Davis, S.A., 2011. Investigating the impact of project managers' emotional intelligence on their interpersonal competence. Project Management Journal, 42(4), 37-57.

Davis, T., Pharro, R., 2003. The Relationship Manager: The Next Generation of Project Management. Gower, Aldershot.

Dolfi, J., Andrews, E.J., 2007. The subliminal characteristics of project managers: an exploratory study of optimism overcoming challenge in the project management work environment. International Journal of Project Management, 25(7), 674-682.

Doloi, H., 2007. Twinning motivation, productivity and management strategy in construction projects. Engineering Management Journal, 19(3), 30-40.

Fong, P.S. and Lung, B.W., 2007. Inter-organizational teamwork in the construction industry. Journal of Construction Engineering and Management, 133(2), 157-168.

Godbold, A., 2003. Managing Ethics, in Turner, J.R. (eds) People in Project Management, Gower, Aldershot, pp. 159-172.

Hadad, Y., Keren, B., Laslo, Z., 2013. A decision-making support system module for project manager selection according to past performance. International Journal of Project Management, 31(4), 532541.

Haynes, N.S., Love, P.E.D., 2004. Psychological adjustment and coping among construction project managers. Construction Management and Economics, 22(4), 129-140.

Ireland, L.R., 1992. Customer satisfaction: the project manager's role. International Journal of Project Management, 10(2), 123-127.

Jelodar, M.B., Yiu, T.W., Wilkinson, S., 2016. A conceptualisation of relationship quality in construction procurement. International Journal of Project Management, 34(6), 997-1011. 
Kuster, J., Huber, E., Lippmann, R., Schmid, A., Schneider, E., Witschi, U., Wüst, R., 2015. Project Management Handbook. Springer, Berlin.

Liebowitz, J., Megbolugbe, I., 2003. A set of frameworks to aid the project manager in conceptualizing and implementing knowledge management initiatives. International Journal of Project Management, 21(3), 189-198.

Malach-Pines, A., Dvir, D., Sadeh, A., 2009. Project manager-project (PM-P) fit and project success. International Journal of Operations and Production Management, 29(3), 268-291.

Mazur, A.K., Pisarski, A., 2015. Major project managers' internal and external stakeholder relationships: the development and validation of measurement scales. International Journal of Project Management, 33(8), 1680-1691.

Meng, X., 2012. The effect of relationship management on project performance in construction. International Journal of Project Management, 30(2), 188-198.

Meng, X., 2015. The role of trust in relationship development and performance improvement. Journal of Civil Engineering and Management, 21(7), 845-853.

Miozzo, M., Dewick, P., 2004. Innovation in Construction: A European Analysis, Edward Elgar, Cheltenham.

Mohammadi, F., Sadi, M.K., Nateghi, F., Abdullah, A., Skitmore, M., 2014. A hybrid quality function deployment and cybernetic analytic network process model for project manager selection. Journal of Civil Engineering and Management, 20(6), 795-809.

Mohr, J., Spekman, R., 1994. Characteristics of partnership success: partnership attributes, communication behavior, and conflict resolution techniques. Strategic Management Journal, 15(2), $135-152$.

Müller, R., Turner, J.R., 2007. Matching the project manager's leadership style to project type. International Journal of Project Management, 25(1), 21-32.

Munns, A.K., 1995. Potential influence of trust on the successful completion of a project. International Journal of Project Management, 13(1), 19-24. 
Odusami, K.T., Iyagba, R.R.O., Omirin, M.M., 2003. The relationship between project leadership, team composition and construction project performance in Nigeria. International Journal of Project Management, 21(7), 519-527.

Ogunlana, S., Siddiqui, Z., Yisa, S., Olomolaiye, P., 2002. Factors and procedures used in matching project managers to construction projects in Bangkok. International Journal of Project Management, 20(5), 385-400.

Papke-Shields, K.E., Beise, C., Quan, J., 2010. Do project managers practice what they preach, and does it matter to project success? International Journal of Project Management, 28(7), 650-662.

Pemsel, S., Müller, R., 2012. The governance of knowledge in project-based organizations. International Journal of Project Management, 30(8), 865-876.

Peterson, T.M., 2007. Motivation: how to increase project team performance. Project Management Journal, 38(4), 60-69.

Pinto, J.K., Slevin, D.P., English, B., 2009. Trust in projects: an empirical assessment of owner/contractor relationships. International Journal of Project Management, 27(6), 638-648.

Pryke, S., Smyth, H., 2006. The Management of Complex Projects: A Relationship Approach, Blackwell, Oxford.

Rowlinson, S., Ho, T.K.K., Po-Hung, Y., 1993. Leadership style of construction managers in Hong Kong. Construction Management and Economics, 11(6), 455-465.

Smyth, H., 2015. Relationship Management and the Management of Projects. Routledge, Oxon.

Sommerville, J., Craig, N., Hendry, J., 2010. The role of the project manager: all things to all people? Structural Survey, 28(2), 132-141.

Soanes, C., Hawker, S., 2008. Compact Oxford English Dictionary. Third Edition Revised, Oxford University Press, Oxford.

Sydow, J., Lindkvist. L., DeFillippi, R., 2004. Project-based organizations, embeddedness and repositories of knowledge. Organization Studies, 25(9), 1475-1489. 
Turner, J.R., Müller, R., 2005. The project manager's leadership style as a success factor on projects: a literature review. Project Management Journal, 36(1), 49-61.

Udhayakumar, R., Karthikeyan, P., 2014. Expected leadership qualities for a project manager to manage construction projects. International Journal of Innovation Research and Development, 3(10), 57-61.

Veal, R., 2011. Project Relationship Management, Project Management Institute, Newton Square.

Walker, A., 2015. Project Management in Construction. Sixth Edition, Blackwell, Oxford.

Walker, D., Hampson, K., 2003. Procurement Strategies: A Relationship-based Approach. Blackwell, Oxford.

Walker, D.H.T., Loosemore, M., 2003. Flexible problem solving in construction projects on the National Museum of Australia project. Team Performance Management: An International Journal, 9(1/2), 515.

Walker, N., 2013 Identifying and Building key Relationships, in Lock, D., Scott, L. (eds) Gower Handbook of People in Project Management, Gower, Aldershot, pp. 231-242.

Wang, C.M., Xu, B.B., Zhang, S.J., Chen, Y.Q., 2016. Influence of personality and risk propensity on risk perception of Chinese construction project managers. International Journal of Project Management, 34(7), 1294-1304.

Whitley, R., 2006. Project-based firms: new organizational forms or variations on a theme? Industrial and Corporate Change, 15(1), 77-99.

Wong, E.S., Then, D., Skitmore, M., 2000. Antecedents of trust in intra-organizational relationships within three Singapore public sector construction project management agencies. Construction Management and Economics, 18(7), 797-806.

Yang, L.R., Huang, C.F., Wu, K.S., 2011. The association among project manager's leadership style, teamwork and project success. International Journal of Project Management, 29(3), 258-267.

Yeung, J.F.Y., Chan, A.P.C., Chan, D.W.M., 2009. Developing a performance index for relationshipbased construction projects in Australia: Delphi study. Journal of Management in Engineering, 25(2), 59-68. 
Yeung, J.F.Y., Chan, A.P.C., Chan, D.W.M., 2012. Defining relational contracting from the Wittgenstein family-resemblance philosophy. International Journal of Project Management, 30(2), 225-239.

Zavadskas, E.K., Turskis, Z., Tamošaitienè, J., Marina, V., 2008. Multi-criteria selection of project managers by applying grey criteria. Technological and Economic Development of Economy, 14(4), 462-477.

Zhang, L., Fan, W., 2013. Improving performance of construction projects: a project manager's emotional intelligence approach. Engineering, Construction and Architectural Management, 20(2), 195-207. 
Table 1

Impact of relationship management on project performance.

\begin{tabular}{|c|c|c|c|c|c|c|c|c|}
\hline & & \multirow[b]{2}{*}{$\begin{array}{l}\text { Mean } \\
(\mathrm{n}=73)\end{array}$} & \multirow[b]{2}{*}{ Std. Dev. } & \multirow[b]{2}{*}{ Ranking } & \multicolumn{2}{|c|}{ Project type } & \multicolumn{2}{|c|}{$\begin{array}{c}\text { Independent sample } \\
\text { t-test }\end{array}$} \\
\hline & & & & & $\begin{array}{l}\text { Newly built } \\
\quad(\mathrm{n}=48)\end{array}$ & $\begin{array}{c}\text { Repair or } \\
\text { refurbishment } \\
(\mathrm{n}=25)\end{array}$ & $t$ & Sig. \\
\hline \multirow{4}{*}{$\begin{array}{l}\text { Internal } \\
\text { relationship }\end{array}$} & $\begin{array}{l}\text { Impact of IRM on } \\
\text { time performance }\end{array}$ & 4.2603 & 0.70764 & 2 & 4.3542 & 4.0800 & 1.587 & 0.117 \\
\hline & $\begin{array}{l}\text { Impact of IRM on } \\
\text { cost performance }\end{array}$ & 4.4247 & 0.64373 & 1 & 4.4375 & 4.4000 & 0.235 & 0.815 \\
\hline & $\begin{array}{l}\text { Impact of IRM on } \\
\text { quality performance }\end{array}$ & 3.9178 & 0.68218 & 3 & 4.0833 & 3.6000 & 3.032 & 0.003 \\
\hline & $\begin{array}{l}\text { Impact of IRM on } \\
\text { client satisfaction }\end{array}$ & 3.7260 & 0.58358 & 4 & 3.8125 & 3.5600 & 1.780 & 0.079 \\
\hline \multirow{4}{*}{$\begin{array}{l}\text { External } \\
\text { relationship }\end{array}$} & $\begin{array}{l}\text { Impact of ERM on } \\
\text { time performance }\end{array}$ & 4.0137 & 0.67686 & 3 & 4.1667 & 3.7200 & 2.800 & 0.007 \\
\hline & $\begin{array}{l}\text { Impact of ERM on } \\
\text { cost performance }\end{array}$ & 4.0685 & 0.71354 & 2 & 4.2292 & 3.7600 & 2.789 & 0.007 \\
\hline & $\begin{array}{l}\text { Impact of ERM on } \\
\text { quality performance }\end{array}$ & 3.8082 & 0.65949 & 4 & 3.9792 & 3.4800 & 3.269 & 0.002 \\
\hline & $\begin{array}{l}\text { Impact of ERM on } \\
\text { client satisfaction }\end{array}$ & 4.6301 & 0.48611 & 1 & 4.7083 & 4.4800 & 1.941 & 0.056 \\
\hline
\end{tabular}


Table 2

Rotated component matrix for internal roles of a project manager.

\begin{tabular}{|c|c|c|c|c|c|c|}
\hline Component & 1 & 2 & 3 & 4 & 5 & 6 \\
\hline \multicolumn{7}{|l|}{ 1. Intra-organization communication and trust } \\
\hline Encouraging open and effective communication between team members & 0.818 & & & & & \\
\hline Fostering trust between different team members & 0.795 & & & & & \\
\hline Creating good communication channels with team members & 0.794 & & & & & \\
\hline Developing trust between project manager and team members & 0.772 & & & & & \\
\hline Listening carefully and responding actively to team members & 0.515 & & & & & \\
\hline \multicolumn{7}{|l|}{ 2. Team cohesion and motivation } \\
\hline Drawing individual interests towards overall project objectives & & 0.758 & & & & \\
\hline Clear definition of roles and responsibilities for team members & & 0.628 & & & & \\
\hline Encouraging team members to work together rather than work alone & & 0.618 & & & & \\
\hline Influencing team members to follow project manager & & 0.595 & & & & \\
\hline Motivating team members for better work performance & & 0.577 & & & & \\
\hline \multicolumn{7}{|l|}{ 3. Conflict resolution and equal treatment } \\
\hline Facilitating the resolution of conflicts within the team & & & 0.848 & & & \\
\hline Ensuring equal treatment for different team members & & & 0.821 & & & \\
\hline \multicolumn{7}{|l|}{ 4. Empowerment and team morale } \\
\hline Promoting morale for the whole team & & & & 0.810 & & \\
\hline Enhancing confidence of team members & & & & 0.629 & & \\
\hline Empowering team members to do what they think are right & & & & 0.570 & & \\
\hline \multicolumn{7}{|l|}{ 5. Senior management support } \\
\hline Seeking understanding and support from senior management & & & & & 0.870 & \\
\hline Maintaining a regular liaison with senior management in the company & & & & & 0.855 & \\
\hline \multicolumn{7}{|l|}{ 6. Learning and innovation } \\
\hline Cultivating a culture of learning and innovation within the team & & & & & & 0.767 \\
\hline
\end{tabular}

Extraction Method: Principal Component Analysis.

Rotation Method: Varimax with Kaiser Normalization.

Rotation converged in 7 iterations. 
Table 3

Rotated component matrix for external roles of a project manager.

\begin{tabular}{|c|c|c|c|c|c|}
\hline Component & 1 & 2 & 3 & 4 & 5 \\
\hline \multicolumn{6}{|l|}{ 1.Inter-organizational communication, trust and long-term business } \\
\hline Developing long-term business relationship with client & 0.845 & & & & \\
\hline Developing long-term business relationships with suppliers & 0.791 & & & & \\
\hline Developing trust between own team and other project parties & 0.736 & & & & \\
\hline Facilitating open and effective communication between own team and other project parties & 0.687 & & & & \\
\hline \multicolumn{6}{|l|}{ 2.Collaborative working between project parties } \\
\hline Making a joint effort with other project parties for problem solving when problems arise & & 0.793 & & & \\
\hline Concentrating on problem solving rather than allocating blame between project parties & & 0.656 & & & \\
\hline Involving in clear definition of roles and responsibilities for different project parties & & 0.632 & & & \\
\hline Leading own team to satisfy client organization & & 0.575 & & & \\
\hline Encouraging collaborative working between own team and other project parties & & 0.523 & & & \\
\hline Making decisions jointly with other project parties when necessary & & 0.502 & & & \\
\hline \multicolumn{6}{|l|}{ 3. Mutual understanding and objectives } \\
\hline Contributing to the mutual understanding of each other's concerns and expectations & & & 0.865 & & \\
\hline Contributing to the establishment of mutual objectives between project parties & & & 0.682 & & \\
\hline Listening carefully and actively responding to concerns raised by other project parties & & & 0.566 & & \\
\hline Promoting benefit and risk sharing between own team and other project parties & & & 0.500 & & \\
\hline \multicolumn{6}{|l|}{ 4. Working with other project stakeholders } \\
\hline Maintaining good relationships with other stakeholders, such as trade unions and public media & & & & 0.913 & \\
\hline Establishing a good dialogue with local communities & & & & 0.912 & \\
\hline \multicolumn{6}{|l|}{ 5. Compliance with contracts and regulations } \\
\hline Keeping commitments to contractual agreements & & & & & 0.807 \\
\hline Complying with government policies and regulations & & & & & 0.784 \\
\hline
\end{tabular}

Extraction Method: Principal Component Analysis.

Rotation Method: Varimax with Kaiser Normalization.

Rotation converged in 7 iterations. 